\title{
La debida diligencia judicial y la protección de los derechos humanos de las mujeres en contextos de violencia
}

\section{Due diligence and protection of women's human rights in contexts of violence}

https://doi.org/10.15332/iust.v0i16.2401

\section{Alejandro Gómez Restrepo}

Abogado, Universidad Pontifica Bolivariana, e investigador del grupo de Investigación sobre Estudios Críticos de la Universidad Pontificia Bolivariana. Estudiante avanzado de Ciencias Politicas de la misma universidad. Correo electrónico: alejogo24-18@hotmail.com

\section{Diana Fernanda Herrera Tovar}

Investigadora, Universidad Pontifica Bolivariana, e investigadora del grupo de Investigación sobre Estudios Criticos de la Universidad Pontificia Bolivariana. Estudiante avanzada de Ciencias Politicas de la misma universidad. Correo electrónico: dianaf.herrera@upb.edu.co

\begin{abstract}
Resumen
En el presente texto se plasman dos aspectos, primero: el difícil ingreso al sistema de administración de justicia para las mujeres víctimas y, segundo, el predominante panorama de impunidad. Estas situaciones serán vistas desde dos elementos: La debida diligencia como obligación reforzada en materia de derechos humanos y, los derechos a las garantías judiciales y a la protección judicial de las mujeres. Se pretende demostrar que al adoptar medidas de debida diligencia, estas permitan proteger los derechos a las garantías judiciales y la protección judicial de las mujeres en contextos de violencia, especialmente, en aquellos casos de violencia sexual donde se torna más complejo su acceso a la justicia.
\end{abstract}

Palabras clave: Debida diligencia judicial, derechos humanos, violencia.

\section{Summary}

In this text, two aspects are expressed first, the difficult access for women victims to enter the justice administration system, and, second, the prevailing panorama of impunity. These situations will be seen from two elements: Due diligence as a reinforced human rights obligation. The rights to judicial guarantees and the judicial protection of women. It is intended to demonstrate that by adopting due diligence measures, these allow the protection of the rights to judicial guarantees and the judicial protection of women in contexts of violence, especially in those cases of sexual violence where their access to justice becomes more complex.

Keywords: Due diligence, human rights, violence. 


\section{Résumé}

Dans ce texte, deux aspects sont exprimés en premier lieu, l'accès difficile des femmes victimes au système d'administration de la justice et, deuxièmement, le panorama dominant de l'impunité. Ces situations seront perçues sous deux aspects: la diligence raisonnable en tant qu'obligation renforcée en matière de droits de l'homme, le droit aux garanties judiciaires et la protection judiciaire de la femme. L'objectif est de démontrer qu'en adoptant des mesures de diligence raisonnable, elles permettent de protéger les droits aux garanties judiciaires et la protection judiciaire des femmes dans des contextes de violence, en particulier dans les cas de violence sexuelle où leur accès à la justice devient plus complexe.

Mots-clés: Due diligence, droits de l'homme, violence. 


\title{
La debida diligencia judicial y la protección de los derechos humanos de las mujeres en contextos de violencia $^{1}$
}

\author{
Alejandro Gómez Restrepo \\ Diana Fernanda Herrera Tovar
}

\section{INTRODUCCIÓN}

En Latinoamérica, especialmente en Colombia, existe una cantidad alarmante de casos sobre violencia sexual contra la mujer. Según la Dirección de Investigación Criminal e INTERPOL de la Policía Nacional (DIJIN) y el Instituto Nacional de Medicina Legal y Ciencias Forenses (INML-CF) "hubo un aumento en el 2016 del $35.93 \%$, en el cual por lo menos una mujer fue agredida sexualmente en una frecuencia de 20,9 a 28,8 minutos" (Corporación SISMA Mujer, 2017, p. 5). A pesar de ser un sujeto vulnerable para sufrir violencia, el acceso a la justicia tanto material como formal ${ }^{2}$ es más difícil para las mujeres.

Desde el 2000 hasta el 2012, en el registro de la Fiscalía General de la Nación (FGN), el número de entradas de casos sobre violencia hacía la mujer, solo por el delito tipificado como acceso carnal violento, fue de treinta y siete (37), de los cuales solo diecinueve (19) se encuentran en un estado de investigación preliminar. Lo anterior quiere decir que el 51.4\% de los casos logró ingresar al sistema, y que solo (trece) 13 lograron posicionarse en la etapa procesal de instrucción. En consecuencia, menos del $40 \%$ de los casos que ingresaron al sistema fueron tramitados (Guzmán, 2013, p. 53). En este mismo sentido, la FGN informó que "entre enero de 2016 y el 10 de marzo de 2017, solo el 2,04\% de casos alcanzaron una sentencia condenatoria" (Corporación SISMA Mujer, 2017, p. 6).

De lo mencionado anteriormente, se plasman dos evidencias: primero, el difícil ingreso para las mujeres víctimas al sistema de administración de justicia, $\mathrm{y}$, segundo, el predominante panorama de impunidad. La situación mencionada, se encuentra en un contraste negativo de acuerdo con lo establecido por organismos internacionales sobre la debida diligencia que deben tener los Estados ante este tipo

1 Este artículo se realiza en el marco de los resultados del proyecto de investigación Otras formas de pensar lo común: límites y posibilidades de la democracia por venir. Radicado 690B-09/1677 (CIDI/UPB). Grupo de Investigación sobre Estudios Críticos de la Universidad Pontificia Bolivariana.

2 Justicia formal es la posibilidad de acceder a los tribunales y procedimiento. La justicia material es aquella que incluye todos los elementos que imposibilitan una participación sustantiva destinada a garantizar la satisfacción de derechos (Guzmán, 2013). 
de situaciones, ya que esta obligación reforzada estatal debe estar conformada por prácticas que permitan actuar de una manera eficaz ante las denuncias; dado que su ausencia en la investigación desde las primeras fases deriva en la impunidad de los hechos vulneratorios.

Si los Estados cumplen con esta obligación en el ámbito judicial se podrá proteger el derecho a las garantías judiciales y protección judicial de las mujeres en contexto de violencia. En general, el derecho procesal se constituye como un instrumento esencial para la protección y el ejercicio pleno de los derechos humanos de los ciudadanos, y puntualmente, en contextos como el colombiano, se constituye aún más necesario especialmente frente a las mujeres víctimas de violencia sexual. Es por lo que esta investigación busca responder a la pregunta ¿En qué sentido adoptar medidas de debida diligencia permite proteger los derechos a las garantías judiciales y protección judicial en contextos de violencia sexual contra la mujer?

\section{LA DEBIDA DILIGENCIA COMO OBLIGACIÓN REFORZADA EN MATERIA DE DERECHOS HUMANOS}

Actualmente, la debida diligencia como obligación reforzada en materia de derechos humanos es uno de los temas con mayor relevancia en campos de determinación de responsabilidad internacional de los Estados Parte ${ }^{3}$, teniendo, últimamente, especial fuerza e incidencia en temas sobre violencia de género. Por lo anterior, en este apartado se hablará en un primer momento sobre el fundamento jurídico, las obligaciones y las consecuencias que se desprenden de esta obligación; en un segundo momento, se desarrollarán las implicaciones y aspectos de la debida diligencia reforzada en caso de violencia contra la mujer, y en tercer momento, se finalizará con una conclusión sobre lo mencionado.

La debida diligencia de los Estados frente a los derechos humanos tiene como fundamento jurídico los artículos 1.1 y 2 de la Convención Americana sobre Derechos Humanos $(\mathrm{CADH})$. Estos son esenciales para determinar las obligaciones que tienen los Estados en el ámbito interamericano, de los cuales se deriva su responsabilidad internacional. El alcance de estos artículos ha sido determinado por los órganos de aplicación de la CADH: la Comisión Interamericana de Derechos Humanos (CIDH) y la Corte Interamericana de Derechos Humanos (Corte IDH).

Las obligaciones que se derivan de estos artículos de la CADH son dos: el respeto y la garantía de los derechos humanos. La primera, según el texto

3 Con el fin de salvaguardar los derechos esenciales en el continente americano, en noviembre de 1969 se celebró en San José de Costa Rica la Conferencia Especializada Interamericana sobre Derechos Humanos, en la que se creó la Convención Americana sobre Derechos Humanos. Esta entró en vigor el 18 de julio de 1978. Hasta la fecha veinticinco naciones americanas han ratificado la Convención, a las cuales se les conoce como Estados Parte y son quienes deben cumplir a cabalidad con las exigencias que de la Convención se desprenden. 
literal, consiste en "respetar los derechos y libertades reconocidos en ella" (Organización de los Estados Americanos, 1969, p. 26), siendo estos, el límite para el ejercicio de la función pública, debido a que solo pueden intervenir en la esfera de los derechos de forma limitada y condicionada. La segunda obligación es aquella garantía que deben brindar los Estados a quienes se encuentren bajo su jurisdicción de ejercer de forma libre y plena los derechos reconocidos en la Convención. Esta obligación está compuesta de dos aspectos, en tanto no solo deben permitir el libre ejercicio de los derechos, sino que también implica la adecuación de todo el aparato gubernamental para tener la capacidad de asegurar, formal y materialmente, la consolidación de los derechos humanos. Lo anterior implica la obligación de prevenir, investigar, sancionar y restablecer en la medida de lo posible, toda vulneración que pueda presentarse a los derechos.

La infracción de estas obligaciones, en principio, son atribuibles al Estado por actos emanados del poder público o de agentes estatales. No obstante, esta no es la única forma de imputar responsabilidad internacional a los Estados Parte por la violación a los derechos contenidos en la Convención, ya que también es posible cuando por actos de terceros se ve vulnerado un derecho y el Estado no ejerció la debida diligencia de su aparato estatal para prevenir o resarcir tal violación. Esto, toda vez que, como lo ha reiterado la Corte IDH en su jurisprudencia, los Estados Parte tienen el deber jurídico internacional de prevenir e investigar con los medios adecuados las violaciones a derechos humanos ejercidas dentro de su jurisdicción. Lo anterior, con el fin de identificar a los responsables para imponerles la medida pertinente y asegurar una reparación idónea a la víctima (Caso Velásquez Rodríguez Vs. Honduras, 1988).

En consecuencia, una vez que las autoridades tengan conocimiento del hecho, deberán iniciar una investigación "seria, imparcial y efectiva" (Caso Juan Humberto Sánchez Vs. Honduras, 2003, p. 79). Esta obligación, aunque no sea de resultado sino de medio, es menester que sea empleada con toda la diligencia que el caso amerite, y no sea realizada como una simple formalidad, generando que sea improductiva desde sus inicios. Por el contrario, la actuación del Estado debe ser la de asumir la investigación como un deber jurídico propio, y no como una gestión de intereses particulares. Todo esto en aras de determinar la verdad y evitar la impunidad de los hechos vulneratorios, dado que esta última es la base para que se puedan presentar, eventualmente, nuevas y reiteradas violaciones a derechos humanos (Caso González y otras ("Campo Algodonero") Vs. México, 2009, p. 76).

Ahora bien, la mujer recientemente ha sido reconocida, en instancias nacionales e internacionales, como un sujeto de especial protección, debido a las vulneraciones que estas han tenido que soportar a través del tiempo por razones de estereotipos de género negativos y perjudiciales. A raíz del reconocimiento de esta problemática, se han creado instrumentos y organizaciones para su protección. A nivel internacional han surgido varios elementos, pero, puntualmente, 
la CEDAW ${ }^{4}$ y la Convención Belém do Pará5; por su parte, Colombia en la Ley 1257 de 2008 define lo que se entiende por violencia contra la mujer y además reforma disposiciones que se encuentran en el Código Penal, el Código de Procedimiento Penal y la Ley 294 de 1996, para que se encuentren en armonía con la nueva definición y protección que allí se aporta (Calle, 2013).

Por lo mencionado, la debida diligencia frente a violaciones a derechos humanos contra las mujeres encuentra un refuerzo a ese deber con las normas específicas que componen el cuerpo normativo internacional que han adoptado los Estados Parte en el tratado Interamericano de la Convención Belém do Pará (CBP). Este tratado en su artículo 7.b obliga a los Estados a "actuar con la debida diligencia para prevenir, investigar y sancionar la violencia contra la mujer" (Organización de los Estados Americanos, 1994). En este sentido es de particular importancia que las autoridades que hayan tenido conocimiento, se hagan cargo de la investigación con determinación y eficacia, para que su actuación sea un mensaje contundente para la sociedad del rechazo de la violencia contra la mujer.

De igual forma, la $\mathrm{ONU}^{6}$, el Comité de la $\mathrm{CEDAW}^{7}$ y la Relatora Especial de la ONU, determinaron que la responsabilidad del Estado también puede darse por actos de terceros siempre y cuando no hayan empleado una debida diligencia para investigar y castigar la vulneración del derecho, específicamente, en mujeres. Haciendo énfasis cada uno de estos, que, en contextos de violencia generalizada contra la mujer, la obligación de debida diligencia se encuentra constituida por más elementos, ya no teniendo que ser simplemente una investigación efectiva, sino exhaustiva, la cual deberá regirse con base en una perspectiva de género y la situación concreta de vulnerabilidad de la víctima (ONU, 2013). El acceso a la información sobre el estado de la investigación por parte de la víctima también tiene un papel principal en el aspecto ampliado de la debida diligencia.

De acuerdo con lo que se ha venido desarrollando, tanto en la doctrina como en la jurisprudencia, para que la debida diligencia empleada por un Estado Parte sea idónea de acuerdo con los estándares internacionales, debe tener: primero, un marco jurídico adecuado de protección, es decir, que todas sus leyes, reglamentos y acuerdos que son directrices de actuación de su aparato gubernamental se encuentren integradas por medidas jurídicas que protejan efectivamente a las mujeres de sus agresores. También, que su normativa no perpetúe prácticas de violencia contra las mujeres y que establezcan procedimientos legales que aseguren a las mujeres víctimas de violencia acceso a la justicia y al debido proceso. Segundo, contar con políticas de prevención frente a factores de riesgo, teniendo como finalidad

4 Convención sobre la eliminación de todas las formas de discriminación contra la mujer.

5 Convención Interamericana para Prevenir, Sancionar y Erradicar la Violencia contra la Mujer (Belém do Pará).

6 ONU (1993). Resolución de la Asamblea General 48/104 del 20 de diciembre de 1993, artículo 4.

7 Comité CEDAW, 29 de enero de 1992. Recomendación general No. 19. 
eliminar todo tipo de prácticas que refuercen ideas o actitudes de maltrato hacía la mujer. Tercero, es de vital importancia el fortalecimiento de las instituciones para que puedan brindar respuestas efectivas a las mujeres en casos de violencia (Caso González y otras (“Campo Algodonero") Vs. México, 2009, p. 70)

En conclusión, los Estados Parte deberán reforzar la debida diligencia en casos de violencia contra la mujer, como obligación que se desprende de los artículos 1.1 y 2 de la CADH y 7 de la CBP; la cual deberá estar compuesta de aspectos diferenciadores y específicos en relación con la debida diligencia que se debe prestar en otras situaciones de vulneración a los derechos humanos, dado que la mujer ha sido reconocida como sujeto de especial protección. A su vez, la inobservancia del refuerzo a la debida diligencia en esta situación específica puede llevar a la responsabilidad internacional del Estado Parte.

\section{LOS DERECHOS A LAS GARANTÍAS JUDICIALES Y A LA PROTECCIÓN JUDICIAL DE LAS MUJERES}

El debido proceso es la base de todos los sistemas de protección de derechos humanos que tienen los Estados Parte, su efectividad es lo que hace posible la medición de la evolución de estos sistemas. Su avance se califica en la garantía de realización, tanto en la teoría como en la práctica del marco jurídico de los derechos humanos implementados en cada aparato gubernamental. El cumplimiento del debido proceso frente a la vulneración de un derecho humano es una evaluación transversal de cualquier instancia de poder público. Su fundamento jurídico se encuentra principalmente en los artículos 8 y 25 de la CADH (Salmón, 2012, p. 85).

El artículo 8 de la CADH consagra las garantías judiciales que debe brindar cada Estado Parte a actos que sean emanados por este y que puedan afectar derechos. El fundamento de existencia de las garantías consagradas y exigidas a cada Estado por parte del artículo 8 es el de generar las suficientes barreras de protección para que los procedimientos en los cuales la actuación del Estado determina el rumbo de los derechos y deberes no sea completamente arbitraria, ni generando vulneraciones a derechos humanos. Si bien allí se hace un especial énfasis de las garantías en el proceso penal, estas no solo se restringen a estos procesos, también incluye todos lo concerniente con los procesos administrativos, laborales y civiles (Salmón, 2012, p. 85).

El artículo 25, por su parte, contiene todo lo referente a la protección judicial. La Corte IDH a través de una Opinión Consultiva menciona que "este es entendido como el procedimiento judicial sencillo y breve que tiene por objeto la tutela de todos los derechos reconocidos por las constituciones y leyes de los Estados Parte y por la Convención" (Corte Interamericana de Derechos Humanos, 1987). El artículo

8 En el mismo sentido Caso Veliz Franco y otros Vs. Guatemala. Excepciones Preliminares, Fondo, Reparaciones y Costas. Sentencia de 19 de mayo de 2014. 
referido se compone de tres elementos, a saber: el primero, es la autoridad competente ante la cual se presenta el recurso; el segundo, es que debe constar de un recurso efectivo y, tercero, los derechos por los cuales se puede interponer una petición ante la Corte IDH. Frente a este último elemento, en comparación con los otros sistemas de derechos humanos, la $\mathrm{CADH}$ incluye una disposición amplia e integradora, dado que establece la posibilidad de presentar el recurso para proteger "derechos fundamentales reconocidos por la Constitución, la ley o la presente Convención" (Organización de los Estados Americanos, 1969).

La indispensabilidad del artículo 25 para la tutela de los derechos humanos es innegable y sus características completamente necesarias para una correcta reparación y debida sanción a quienes incurran en un hecho vulneratorio. Estas características son principalmente la efectividad y la idoneidad del recurso. La efectividad, como primera característica con la que debe contar ese recurso, es entendida como la utilidad y cumplimiento de la finalidad por la cual fue creado, que es la posibilidad positiva de alcanzar la protección judicial requerida. De igual forma, los recursos deben generase con base en las reglas del debido proceso legal al que hace referencia el artículo 8, el cual debe ser regido siempre por la obligación contenida en el artículo 1.1 de la CADH. Así mismo, esta característica no solo comprende el acceso de la víctima al aparato gubernamental, sino también el derecho a obtener un pronunciamiento definitivo dentro de un plazo razonable (Caso Bayarri Vs. Argentina, 2008).

La segunda característica, la idoneidad del recurso, hace referencia a la capacidad de este para proteger y resarcir la relación jurídica infringida. De allí se deriva que no siempre todos los recursos que se tengan dentro del ordenamiento interno son idóneos para dar solución a la situación de vulneración, dado que la adecuación del recurso dependerá estrictamente del derecho vulnerado. Lo anterior genera dos consecuencias: la primera es que aunque un recurso sea idóneo para una situación no significa que lo será para todas, y, segundo, no será necesario acudir siempre a los recursos pre-establecidos, pero que son inidóneos para el caso en concreto, sin que esto pueda ser una excusa para la inactividad del Estado en remediar esa situación por medio de otro recurso, esto porque tal actuación derivaría en el incumplimiento del deber a la protección judicial. A su vez, si el caso es la no existencia del recuso idóneo, por medio del artículo 2 de la CADH se crea la obligatoriedad para los Estados de instaurar uno (Caso del Pueblo Saramaka Vs. Surinam, 2007, p. 53).

Ahora bien, el debido proceso frente a casos de violencia contra la mujer se encuentra robustecido por el artículo 7 de la CBP, la doctrina, los mecanismos especiales de protección para la mujer y la jurisprudencia de la Corte IDH. En estos se encuentran establecidos unos parámetros específicos más amplios que los generales, los cuales son: el establecimiento de procedimientos legales justos, eficaces, accesibles, oportunos, que consten de premura, imparcialidad, y, como se mencionó anteriormente, exhaustivos y no solo efectivos; en este mismo sentido "la adopción de normas penales, civiles y administrativas para prevenir, sancionar y 
erradicar la violencia contra la mujer" (Organización de los Estados Americanos, 1994, p. 3).

Lo anterior, como lo ha mencionado la CIDH y la Corte IDH, implica la garantía al derecho a la privacidad; que los procedimientos no estén conformados por trámites altamente formales; que el recurso sea mucho más sencillo y corto en comparación con otros; la disponibilidad y adecuación del aparato gubernamental en cada parte del Estado para la atención pronta de la mujer víctima; el fortalecimiento de las capacidades de los agentes Estatales para llevar este tipo de casos de una forma idónea sin generar una revictimización y salvaguardando siempre los derechos de la víctima; que el costo de los procesos no generen una exclusión a quienes también padecen de esta vulneración, pero no cuentan con los medios, $\mathrm{y}$, por último, y siendo la más importante, que las medidas de protección que se les brinda sean efectivas para protegerlas de actos de violencia inminentes por su principal maltratador.

En suma, de no incorporarse y garantizarse el cumplimiento de los mandatos que se mencionaron se seguirán presentando múltiples inconsistencias. Una de ellas será que los inconvenientes del difícil acceso a la justicia y el incumplimiento al debido proceso a los que se enfrentan las mujeres víctimas no cesaran. Igualmente, la impunidad de los agresores seguirá siendo una realidad social con la que se enfrentan las víctimas, cohibiéndolas de gozar de sus vidas libres de temor. Asimismo, en caso de no cumplirse con esto se promueve la tolerancia de este fenómeno social.

\section{LA DEBIDA DILIGENCIA JUDICIAL FRENTE A LA VIOLENCIA SEXUAL EN MUJERES}

En su artículo primero, la CBP ha entendido la violencia contra la mujer como “(...) Cualquier acción o conducta, basada en su género, que cause muerte, daño o sufrimiento físico, sexual o psicológico a la mujer” (Organización de los Estados Americanos, 1994). Se comprende dentro de esa definición la violación, el abuso sexual, la tortura, la trata de personas, la prostitución forzada, el secuestro y el acoso sexual. En el artículo 2, la CBP visibiliza tres ámbitos de manifestación de este tipo de violencia, los cuales son: la vida privada, la vida pública y la perpetrada o tolerada por el Estado donde quiera que ocurra. En este mismo sentido, tanto la CIDH como la Corte IDH han entendido la violencia contra la mujer y han dotado de contenido y alcance esta definición.

De ahí que la Corte IDH haya reconocido que cuando una mujer es forzada a desnudarse, a soportar manoseos, a ser tocada y maltratada en sus partes íntimas y genitales, esos actos constituyen violencia sexual. En este mismo sentido, ha establecido que la violencia sexual "se configura con acciones de naturaleza sexual que se cometen contra una persona sin su consentimiento, que además de comprender la invasión física del cuerpo humano, pueden incluir actos que no involucren penetración o incluso contacto físico alguno" (Caso del Penal Miguel Castro Castro Vs. Perú, 2006, p. 105). En general, en la línea jurisprudencial referente a esta 
problemática, la Corte ha establecido que el perjuicio va más allá de ser solo físico, también afecta la moralidad e integridad de la víctima, puesto que es uno de los actos más vulneratorios a derechos humanos, el cual transciende a afectar no solo a la víctima sino a la sociedad en general.

En otro sentido, agrega la CIDH que se debe tomar en consideración la combinación de factores de riesgo que ponen en un ámbito potenciado de vulnerabilidad a la mujer, como lo es el sexo, la edad, su posición económica, discapacidades que padezca o su etnia. Un ejemplo claro es la situación a la que se ven enfrentadas cientos de niñas, quienes por su edad son más vulnerables a ser víctimas de violencia sexual, siendo su agresor el hombre como protagonista de este acto. De acuerdo con las estadísticas presentadas por el Instituto Colombiano de Bienestar Familiar (ICBF) en el 2016: de 21.868 niños, niñas y adolescentes que fueron víctimas de violencia sexual, 18.435 fueron niñas, teniendo una mayor incidencia en edades que oscilan entre 6 a 12 años, todos estos con una alta impunidad (Instituto Colombiano de Bienestar Familiar, 2016).

En relación con lo mencionado por estos órganos, la Relatora Especial de la ONU ha manifestado que la violencia sexual también es una expresión de discriminación contra la mujer. Esta discriminación no configura un hecho aislado, sino que es el producto de patrones socioculturales. Estos patrones son legitimados y reforzados por los Estados a través de sus actuaciones y la implementación de su ordenamiento interno por políticas y mensajes que incitan a la creencia generalizada de que la dominación masculina frente a la femenina es algo completamente natural y biológicamente sustentable. Estas creencias sociales, en la mayoría de los casos, son reproducidas en las instituciones judiciales, donde los estereotipos permean las decisiones tomadas por sus agentes, restándole importancia a la violencia sexual y amplificando los motivos que la víctima dio para sufrir tal vulneración, como el historial de su vida sexual, si se resistió, el lugar y la hora en donde se encontraba y la vestimenta que la acompañaba (Naciones Unidas, 1999).

Por otro parte, la debida diligencia judicial es el deber de los Estados Parte de respetar los derechos y libertades reconocidos en la $\mathrm{CADH}$, asimismo brindar protección y promover el ejercicio libre de estos en su jurisdicción, por medio de la efectividad en las garantías judiciales y la protección judicial. En casos de violencia sexual, este deber se encuentra reforzado por unos mecanismos especiales, que son creados en atención a la capacitación de los agentes estatales y la adecuación del aparato gubernamental, con la finalidad de reparar de forma íntegra la vulneración soportada por la víctima.

Por la trascendencia e implicaciones que tiene la violencia sexual, tanto en la víctima como en la sociedad, la Corte IDH ha establecido que las obligaciones generales de los artículos 8 y 25 de la $\mathrm{CADH}$, se encuentran reforzados con el mandato que se desprende del artículo 7.b de la CBP. Este y los demás instrumentos internacionales, edifican, dotan de contenido y alcance la obligación estatal, generando, entonces, un deber de refuerzo en la debida diligencia judicial empleada 
por los Estados para "prevenir, sancionar y erradicar la violencia contra la mujer" (Organización de los Estados Americanos, 1994).

Por consiguiente, los aspectos diferenciadores de los mecanismos especiales frente a casos de violencia sexual contra la mujer se pueden distinguir en varias etapas del proceso. Pero una de las más relevantes y de la cual dependen muchos factores del proceso es la etapa de investigación penal. En esta instancia se deberán seguir estrictamente los siguientes requerimientos: primero, recibir la declaración de la víctima en ambientes que le propicien la seguridad y comodidad necesaria para que puedan contar los hechos de los que fue víctima con toda confianza sin sentir que su vida corre peligro; segundo, registrar la declaración en debida forma para evitar a toda costa su repetición, dado que esto genera para la víctima el tener que volver a revivir en su memoria hechos traumáticos; tercero, prestar la asistencia médica requerida para reducir las consecuencias generadas por la violación; cuarto, recolectar y manejar adecuadamente todo lo que compone la prueba y, quinto, el acceso a la justicia gratuito durante todas las fases del proceso (Caso Fernandez Ortega y otro Vs. México, 2010, p. 25).

Por lo mencionado anteriormente, la CIDH destaca que la importancia de una investigación penal adecuada es esencial en estos casos, dado que las fallas en esta etapa pueden crear impedimentos futuros insuperables, que pueden evitar la sanción de los responsables y la debida reparación de la víctima. Así mismo, estos componentes son fundamentales al momento de examinar la debida diligencia y el cumplimiento de la garantía del acceso a la justicia que presta el Estado, pudiendo derivar esto en la responsabilidad internacional. La debida diligencia judicial como obligación reforzada se constata como una medida procesal esencial para garantizar los derechos humanos de las mujeres víctimas de violencia.

De lo anterior, se deriva que el refuerzo de la debida diligencia judicial de ser implementado en los Estados garantizará a las mujeres víctimas de violencia sexual el efectivo cumplimiento de sus derechos procesales de las garantías y la protección judicial. Lo anterior, toda vez que así se les prestaría una atención más minuciosa, evitando que el acceso a la justicia siga siendo difícil e ineficaz. También, por medio de este mecanismo se puede generar una consciencia colectiva del no maltrato hacía la mujer, derrumbando los estereotipos de género y evitando que quienes son víctimas no acudan a la justicia por una eventual revictimización por parte de los agentes estatales.

\section{CONCLUSIONES}

La debida diligencia es una obligación que tienen los Estados al firmar la CADH, la cual se emana de los artículos 1 y 2 que contienen las obligaciones generales de este tratado. Esta obligación se compone de una serie de elementos: actividad de prevención, investigación, juzgamiento, sanción y reparación. En los casos de violencia contra la mujer esta obligación se ve reforzada y debe ser cumplida de 
una manera más exhaustiva, según lo dispone la CBP. Los derechos a las garantías judiciales y a la protección judicial consisten en la existencia de recursos idóneos y efectivos a los que puedan acceder las personas que se vean amedrentadas en sus derechos y que los trámites instaurados se desarrollen bajo el principio del debido proceso; cumpliéndose así con el estándar internacional de debida diligencia se protegen estos dos derechos convencionales.

Las mujeres son sujetos proclives a la violencia en virtud de los patrones machistas arraigados a la cultura. Una vez se vulnera a una mujer producto de actos de violencia, especialmente en casos de violencia sexual, para estas se genera toda una travesía institucional para lograr ser resarcidas. Las autoridades estatales usualmente no permiten un fácil acceso a la justicia y esto genera que muchas mujeres decidan voluntariamente mantener su situación en silencio y no acudir a instancias estatales. Si las autoridades estatales no permiten un acceso a la justicia en condiciones que sean amables y eficaces a las mujeres víctimas, estas estarán sometidas a una revictimización constante.

El cumplimiento de medidas de debida diligencia, particularmente en el ámbito judicial, se torna un imperativo para que las mujeres puedan ver sus derechos a las garantías judiciales y a la protección judicial materializados, y en este sentido, puedan acceder a la justicia y alcanzar un resultado favorable. Las instancias procesales, las autoridades procesales, $y$, en general, un adecuado derecho procesal, se tornan esenciales para materializar los derechos humanos de las mujeres. Es por lo que adoptar medidas de debida diligencia permite proteger los derechos a las garantías judiciales y la protección judicial de las mujeres en contextos de violencia, especialmente, en aquellos casos de violencia sexual donde se torna más complejo su acceso a la justicia.

\section{REFERENCIAS}

Calle, M. E. (2013). Violencia de género. Revista Nuevo Derecho, 11. Institución Universitaria de Envigado.

Caso Bayarri Vs. Argentina (Corte Interamericana de Derechos Humanos 30 de octubre de 2008).

Caso del Pueblo Saramaka Vs. Surinam (Corte Interamericana de Derechos Humanos 28 de noviembre de 2007).

Caso del Penal Miguel Castro Castro Vs. Perú (Corte Interamericana de Derechos Humanos 25 de noviembre de 2006).

Caso Fernández Ortega y otro Vs. México (Corte Interamericana de Derechos Humanos 30 de agosto de 2010).

Caso González y otras (“Campo Algodonero”) Vs. México (Corte Interamericana de Derechos Humanos 16 de noviembre de 2009). 
Caso Juan Humberto Sánchez Vs. Honduras (Corte Interamericana de Derechos Humanos 7 de junio de 2003).

Corte Interamericana de Derechos Humanos. (1987). Opinión Consultiva OC-8/87. San José.

Caso Velásquez Rodríguez Vs. Honduras (Corte Interamericana de Derechos Humanos 29 de julio de 1988).

Corporación Sisma Mujer. (2017). La erradicación de las violencias contra las mujeres: una tarea inaplazable en la construcción de la paz. Bogotá.

Guzmán, D. (2013). Acceso a la justicia. Mujeres, conflicto armado y justicia. Bogotá: Dejusticia.

Instituto Colombiano de Bienestar Familiar. (2016). Reporte nacional de los niños, niñas y adolescentes en proceso administrativo de restablecimiento de derechos, por motivo de ingreso víctimas de violencias sexual, con corte a 31 de mayo de 2016. Bogotá.

Naciones Unidas. (1999). Ejecuciones extrajudiciales, sumarias o arbitrarias.

ONU. (1993). Resolución de la Asamblea General 48/104. ONU.

ONU. (2013). Informe de la relatora especial sobre violencia contra la mujer, sus causas y consecuencias. ONU.

Organización de los Estados Americanos. (1969, 22 noviembre). Convención Americana sobre Derechos Humanos. San José, Costa Rica.

Organización de los Estados Americanos. (s.f.). Convención de Belém do Pará

Organización de los Estados Americanos. (1994). Convención Interamericana para Prevenir, Sancionar y Erradicar la Violencia contra la Mujer (Convención de Belém do Pará). Belém do Pará: OEA.

Salmón, E. (2012). El derecho al debido proceso en la jurisprudencia de la Corte Interamericana de Derehos Humanos. Lima: Instituto de Democracia y Derechos Humanos. 